\title{
TEMPERATURA CORPORAL: PLANEJAMENTO DA ASSISTÊNCIA DE ENFERMAGEM NA VERIFICAÇÄO DA TEMPERATURA; NO ATENDIMENTO DA FEBRE E DA HIPERTERMIA MALIGNA
}

\author{
Thelma Leite de Araijo* \\ Ana Cristina Mancussi e Paro* \\ Maria Teresa Cicero Lagana**
}

ARAÚJO, T.L. de; FARO, A.C.M. e LAGANÁ, M.T.C. Temperatura corporal: planejamento da assistência de enfermagem na verificaçáo da temperatura; no atendimento da febre e da hipertermia maligna. Rev. Esc. Enf. USP, v. 26, n. 3, p. - , dez., 1992.

O presente estudo aborda o planejamento da assistência de enfermagem na verificação da temperatura, na escolha do instrumento de medida; no atendimento ao paciente com febre $e$ com hipertermia maligna. mia maligna.

UNITERMOS: Assistência de enfermagem. Verificação da temperatura. Febre. Hiperter-

\section{Introduçáo}

Neste trabalho enfocamos o planejamento da assistência de enfermagem na verificação da temperatura corporal e no atendimento da febre e da hipertermia maligna, de modo a sugerir açóes de enfermagem oportunas nas intercorrências relacionadas à temperatura corporal.

\section{Planejamento da Assistência}

\subsection{Instrumentos empregados na verificação da temperatura corporal}

\section{Termômetro de mercúrio}

É o mais familiar para os pacientes; consiste de um tubo de vidro com um filamento de mercúrio do bulbo até a extremidade distal, que, com o calor, expande o volume, dando a temperatura na escala de graus Celsius de $35^{\circ}$ a $41^{\circ} \mathrm{C}$; a coluna de mercúrio não deverá flutuar ou diminuir a menos que seja vigorosamente abaixada; a leitura se faz ao nível dos olhos, o bulbo não deverá ser tocado;

- Assistente do Departamento de Enfermagem Médico-Cirurgica da Escola de Enfermagem da USP.

* Professora da Faculdade de Enfermagem do Hospital Israelita Albert Einstein. 
há três tipos: oral, axilar e retal; a forma do termómetro tem o efeito de uma lente de aumento, sendo que o tubo onde está o número tem, aproximadamente, 0,001 até 0,002 polegadas de diâmetro. O mercúrio é metal líquido, de coloraçăo prateada e dentro do termómetro não é absorvível, não ocasionando danos ao paciente; o vidro é um bom dissipador de calor. Quanto maior a superfície do vidro que circunda o mercúrio, tanto mais rápidos serão o aquecimento e a elevação do mercúrio.

\section{Limitações}

Leitura mais difícil conforme o fabricante; necessita mais tempo para leitura; quebra-se facilmente; é relativamente acurado considerando as interferências naturais do corpo, mas não reflete com precisão a temperatura corporal.

Vantagens

Baixo custo; grande disponibilidade no mercado e praticidade de uso.

\section{Termómetro eletrônico}

Consiste de um dispositivo com bateria e leitura eletrónica (digital), com um sensor de temperatura coberto por outro dispositivo plástico que, em se trocando a cada paciente, previne infecção cruzada. Dispositivos intercambiáveis servem para temperatura oral e retal; com apenas poucos segundos de inserção a temperatura pode ser lida; um termometro eletrônico não é necessariamente mais acurado que um termốmetro de mercúrio porque os fatores que interferem na medida deste último afetam, da mesma forma, a medida do termometro eletrónico. Este pode, inclusive, ser menos acurado pelo menor tempo de inserção.

\section{Vantagens}

Apenas poucos segundos de leitura; fácil de ler; mínimo desconforto para o paciente; menos riscos para os pacientes; mais higiênico.

\section{Limitações}

Custo mais alto; necessidade de manutenção; na prática não tem havido diferenças significativas, quanto à precisão, entre os termómetros de mercúrio e eletrônico.

\section{Termometro descartável}

São finas tiras de plásticos com papéis impregnados quimicamente. Servem para temperatura oral e de superfície, são usados da mesma forma que o termómetro de mercúrio. A mudança de cor denota o valor da temperatura a ser lida. São necessários 45 segundos. 


\subsection{Assistência de Enfermagem}

A verificaçăo da temperatura pode não ser rotina. As circunstâncias em que deve ser medida dependem de um plano individualizado para cada paciente, conforme a avaliação da necessidade e da freqüência, determinadas pelo enfermeiro. O planejamento global do cuidado antecede a assistência propriamente dita e inclui os seguintes itens:

1. Conhecer a história médica, o histórico de enfermagem e o esquema terapêutico dos pacientes;

2. Conhecer as variaçóes habituais da temperatura dos pacientes durante a internaçăo, estabelecendo critérios de normalidade individual;

3. Saber controlar os fatores que podem interferir e influenciar na temperatura dos pacientes conforme os mecanismos de ganho e perda de calor;

4. Verificar se os instrumentos para medida estão funcionando e são adequados;

5. Estabelecer rotinas de enfermagem relacionadas a temperatura condizentes com a especialidade da unidade e com o dignóstico do paciente;

6. Determinar claramente para a equipe de enfermagem quais as alteraçōes significativas de temperatura dos pacientes que devem ser imediatamente comunicados para a enfermeira;

7. Prescrever objetivamente os cuidados de enfermagem necessários às alteraçð̃es da temperatura corporal dos pacientes;

8. Determinar, juntamente com a equipe médica, os limites da temperatura corporal dos pacientes indicativos da necessidade de medicação.

9. Estabelecer programas de avaliação de desempenho dos funcionários no que se refere a mensuração de temperatura, para identificar necessidades de reciclagem.

\subsection{Circunstâncias em que a temperatura corporal deve ser medida}

1. Na admissão e alta hospitalar;

2. Nos procedimentos invasivos (sondagem vesical, cateteres intravenosos, etc.)

3. Nos procedimentos diagnósticos (biópsias, cateterismos cardíacos, endoscopias, etc.)

4. Antes e depois de administrar soluções intravenosas como sangue, plasma, soros, etc.; 
5. Quando o paciente relata uma sintomatologia inespecifica;

6. Quando existe alguma alteração significativa da sintomatologia referida pelo paciente que possa ser esclarecida pela medida da temperatura (ex.: aparecimento de dor, secreções, queimação, etc.);

7. Nos casos de abcessos, drenagens, distúrbios hidroeletrolíticos, nutrição parenteral prolongada, sinais de infecçăo e

inflamação e nas alterações importantes dos demais sinais vitais;

8. Antes e depois de cirurgias.

\subsection{Técnica de verificação da temperatura corporal nos locais usualmente utilizados}

Determinar o local mais apropriado para a medida; reunir o material necessário; mãos e termómetro limpos; posicionamento correto do bulbo do termômetro; atenção às substâncias desinfetantes irritantes de pele e mucosa; atenção às indicações e limitações da T. oral, T. axilar e T. retal.

\section{Vantagens e limitações dos locais para verificaçáo da temperatura corporal}

\subsection{Axilar}

Vantagens

Método não invasivo; ideal para recém-nascidos; mais segura para crianças; mais fácil desinfecção; mais difundida em nosso meio.

\section{Limitações}

Medida menos acurada; demora mais tempo para ser feita a leitura; as vezes é difícil manter as crianças quietas por muito tempo; ́́ difícil adaptar bem o termômetro na cavidade azilar; sofre variações de medida, na mesma axila, com maior freqüência; sofre influência das secreções axilares fornecendo leituras menores que as reais; sofre mais influência da temperatura do meio ambiente e umidade relativa do ar, estando sujeita a flutuações muito mais intensas.

\subsection{Bucal}

Vantagens

Fácil acesso; mais fidedigna porque possui rico suprimento sangüíneo; está próxima aos grandes vasos e a corrente sangüínea reflete a temperatura das áreas centrais do corpo. 
Desinfecção mais difícil; pode ser afetada por inúmeros variáveis: fumos, ingestão de líquidos quentes ou frios, goma de mascar, embora em pacientes afebris o fumo e a goma de mascar não determinem diferenças significativas; não deve ser usada se o cliente está recebendo oxigenoterapia contínua, nesses casos há um resfriamento do organismo, com queda, inclusive da temperatura retal, mas há pesquisas que demonstram não haver diferenças dos registros das temperatu-

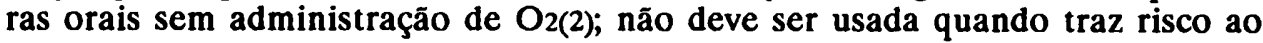
paciente, quando este tem alguma impossibilidade ou quando corre o risco de danificar o termometro. Ex.: crianças pequenas; doentes mentais; pacientes confusos ou inconscientes; com pós-operatório de cirurgia oral, com trauma de face ou boca, com dor de cavidade oral; clientes com história de convulsão ou que respiram somente com a boca aberta; a temperatura é menor se o paciente falar ou respirar pela boca; na nossa cultura não é o mais aceitável nem é considerado confortável; após alimentação ou fumo deve-se aguardar aproximadamente 20' para verificação.

\subsection{Retal}

\section{Vantagens}

É também considerada uma medida de temperatura próxima à temperatura central porque existem poucos fatores que interferem em sua medida. Isto se deve ao fato da temperatura retal não acompanhar tão rapidamente as mudanças da temperatura arterial (como na temperatura sublingual), por representar a quantidade de calor das vísceras abdominais e pélvicas profundas. $O$ fluxo sangüineo nas veias e artérias adjacentes a esta região é relativamente constante. Sendo assim a temperatura retal e mais representativa de uma região específica e não de uma somatória de todas as áreas do corpo.

\section{Limitações}

Em crianças é difícil mantê-las quietas por muito tempo; não se utiliza em recém-nascidos pelo risco de ferir a mucosa retal; não se usa em pacientes com cirurgia retal ou afeç̧ões ano-retais (tumor, hemorróidas, diarréia); nâo se usa em pacientes que não podem se posicionar para a introdução do termometro (pacientes em tração, por ex.); é um procedimento mais contaminado porque tem microorganismos próprios da regiẫo; necessita ambiente privativo; é psicologicamente mais agressivo; acarreta problemas de ordem cultural; há variações de 0,1 a $0,9^{\circ} \mathrm{C}$ dependendo da posição do instrumento de registro.

\section{Cuidados com a colocaçáo do termómetro de mercúrio}

\subsection{Axila}

- Tempo para leitura ${ }^{*}=7$ ' a 11' 
- Valores médios $=35^{5 \circ} \mathrm{C}$ a $37^{2 \circ} \mathrm{C}$

- Local de colocação = na cavidade axilar

- Cuidados = retirar a roupa da axila, deixá-la seca e bem fechada com o bulbo do termometro em contato com a pele.

- Observações = manter o paciente em posição confortável; orientar e supervisionar o paciente; a precisão da temperatura depende do bom posicionamento do bulbo na cavidade axilar.

\subsection{Boca}

- Tempo para leitura ${ }^{*}=3^{\prime}$ a $8^{\prime}$

- Valores médios $=36^{1 \circ} \mathrm{C}$ a $38^{\circ} \mathrm{C}$

- Local de colocação = sublingual posterior $\mathrm{D}$ ou $\mathrm{E}$. Na localização anterior a temperatura é mais baixa.

- Cuidados = paciente sentado, acordado e consciente; retirar o termómetro envolto em lenço de papel evitando contato com secreções bucais.

- Observações = manter paciente em posição confortável; orientar e supervisionar o paciente; em pacientes febris $6^{\prime}$ é suficiente; não conversar com o paciente durante a verificação.

\subsection{Reto}

- Tempo para leitura* $=2^{\prime}$ a 4'

- Valores médios $=36^{6 \circ} \mathrm{C}$ a $38^{6 \circ} \mathrm{C}$

- Local de colocação $=$ no reto: adultos $2,5-3,5 \mathrm{~cm}$.

$$
\text { crianças } 1,2-2,5 \mathrm{~cm} \text {. }
$$

- Cuidados = adultos: posição de Sims. crianças: em pronação.

Usar papel ou luvas se necessário; lubrificar, colocar gentilmente, não fornçar, expor o ânus, introduzir em direção ao umbigo, observar secreções e sangramentos.

- Observações = manter paciente em posição confortável; orientar e supervisionar o paciente; há relevância clínica na temperatura diferencial axilo-retal em processos inflamatórios pélvicos, sendo significativas as diferenças acima de $1^{\circ} \mathrm{C}$.

* em termos de mínimo e ótimo 


\section{Cuidados de enfermagem na hipertermia}

\subsection{Na fase fria}

$\mathrm{Na}$ fase fria onde se observa: sensação de frio, piloereção, arrepios, fortes contrações musculares, palidez, taquicardia, hipertensão e taquipnéia, os cuidados indicados são:

- controle freqüente de sinais vitais;

- manter ainda o paciente aquecido;

- colher hemocultura, caso necessário;

- reduzir atividades físicas mantendo o paciente em repouso e

- observar as variações e o padrão febris.

$\mathrm{Na}$ fase fria, o termostato hipotalâmico começa a fazer o ajuste térmico para elevar a temperatura mas esta, no sangue, ainda $e$ a habitual para $o$ indivíduo e, então, ocorre a vasoconstrição para evitar perda de calor. Para o termostato hipotalâmico conseguir elevar a temperatura, ele estimula as contrações musculares e os arrepios para gerarem calor. Quando a temperatura corporal se iguala ao ajuste hipotalâmico (aproximadamente $38^{\circ} \mathrm{C}-\mathrm{T}$. axilar), $\mathrm{o}$ indivíduo năo ex-perimenta mais arrepios. A presença de calafrios guarda relação com a intensidade da febre e principalmente com a rapidez da elevação térmica, variando de arrepios a tremores intensos.

\subsection{Na fase quente}

$\mathrm{Na}$ fase quente, caracterizada por rubor, calor, irritabilidade do sistema nervoso central, anorexia, náuseas, vômitos, desidratação de pele e mucosas, hipotensão arterial, desorientação e confusão mental em adultos e convulsões nas crianças, os cuidados devem incluir:

- arejar o ambiente e mantê-lo menos iluminado;

- reduzir roupas do paciente e da cama;

- dar banho morno ou fazer compressas frias, na regiāo dos grandes vasos;

- dar antitérmico, conforme indicação;

- oferecer líquidos observando aceitação;

- umedecer lábios;

- manter vigilância quanto ao nível de consciência; 
- controlar a medida da temperatura corporal.

Nesta fase a temperatura corporal está se elevando e o termostato hipotalâmico está se ajustando. Ao estabilizar o ajuste hipotalâmico, comesa a vasodilatação periférica para a perda de calor, onde o afluxo de sangue para a pele pode chegar a $30 \%$ do débito cardíaco total.

A internaçáo, que ocorre a uma temperatura de $41-42^{\circ} \mathrm{C}$, ocasiona hemorragias e degeneração celular, principalmente em órgãos vitais, havendo perigo de morte.

\subsection{Na fase úmida}

$\mathrm{Na}$ fase úmida, onde o paciente apresenta transpiração profusa, vasodilatação, possível desidratação e abaixamento da temperatura, os cuidados de enfermegem indicados são:

- manter a roupa de cama limpa e seca;

- promover higiene oral e corporal;

- oferecer líquidos, 2 a 3 litros/dia, caso não haja contra indicações;

- examinar sinais de desidratação;

- medir volume urinário e

- pesar.

Nesta fase a vasodilatação cutânea já se completou, possibilitando a irradiação, a condução e a evaporação. A sudorese contribui com a metade da perda da evaporação. Para cada 1 litro de água que se evapora são necessárias 580 calorias que são retiradas do organismo, com o conseqüente resfriamento do mesmo. A evaporação da sudorese é a única forma que o indivíduo tem de perder calor quando está com temperatura elevada.

O suor produzido adere-se à pele com grande desconforto térmico, o paciente sente sede e muito cansaço.

\section{Assistência de enfermagem em Hipertermia maligna}

A Hipertermina maligna é uma síndrome determinada por condição genética, com maior incidência em crianças do que em adultos e com mortalidade em torno de $30 \%(1,3,4)$. É desencadeada em situações de anestesia sendo uma das maiores emergências que podem ocorrer desde a fase de indução até a recuperação pós-anestésica. Caracteriza-se por um aumento rápido da temperatura corporal, em média $1^{\circ} \mathrm{C}$ a cada 5 minutos, chegando a níveis superiores a $40^{\circ} \mathrm{C}$, com hiperpnéia, taquicardia, com ou sem rigidez muscular, hipóxia, ansiedade e medo, hipotensão arterial, hiperemia da face, sudorese, torpor, confusão mental e agitação psicomotora; finalizando com acidose metabólica e arritmias cardíacas. 
A incidência varia conforme a idade. Entre 1971 - 1983, a proporçăo foi de 1:15.000 em crianças e de 1:50.000 a 1:100.000 em adultos(4).

A evolução do quadro é rápida e a temperatura não cede com antitérmicos. Nestas condiçóes os cuidados de enfermagem devem ser:

- resfriamento da sala cirúrgica;

- monitorização dos sinais vitais;

- controle da temperatura axilar e retal;

- resfriamento da superfície corporal com compressas embebidas em álcool e água (na proporção aproximada de 1:3) e/ou colocação do paciente em banheira contendo água fria, conforme as possibilidades;

- coleta de sangue para gasometria, sodio/potássio, transaminases, TGO/TGP, EPK, DHL, creatinina, uréia e glicose, para orientar a monitorizaçăo cardíaca e a ventilação respiratória mecânica;

- estabelecimento de duas vias venosas para administração de medicamentos como sedativos, corticoides, corretores de acidose, expansores de plasma, entre outros;

- controle de diurese.

Ressaltamos que pode haver dificuldades para o anestesista entubar o paciente em casos em que há rigidez muscular, sendo importante que a enfermagem medique o paciente, conforme prescrição médica, o mais rapidamente possivel para obter o relaxamento desejável.

Foram registrados casos na literatura $(1,3,4)$ em que se utilizou o resfriamento das cavidades gástricas e vesical com soro fisiológico gelado, bem como a administraçăo de soro fisiologico gelado endovenoso, além de banho de imersăo com água e gelo, em pacientes com idades de 2, 5 e 19 anos, todos do sexo masculino. Nestas condutas a enfermagem deverá prever e providenciar o material necessário; fazer ou ajudar a sondagem gástrica e vesical.

Após 30' da intercorrência, a temperatura do paciente deverá iniciar o abaixamento, atingindo temperatura retal próxima de $37^{\circ} \mathrm{C}$ depois de 1 hora. A monitorização dos sinais vitais e o registro sistemático de observações de sinais e sintomas deverá continuar até $36 \mathrm{~h}$ apos o episodio da hipertermia, juntamente com avaliações periodicas do anestesista.

\section{Conclusões}

A verificação e o controle da temperatura corporal devem ser estabelecidos conforme critérios de julgamento do enfermeiro a partir das necessidades de cuidado do paciente.

A febre (ou pirexia) é uma entidade nosológica bem definida que apresenta características seqüenciais (fase fria, fase quente e fase úmida), relacionadas com o mecanismo de regulação da temperatura corporal. Este mecanismo deve 
ser compreendido pelo enfermeiro para que ele saiba interpretar as reaçōes do organismo e indicar a assistência de enfermagem adequada.

A Hipertermia maligna é um fenómeno raro cuja mortalidade era superior a $70 \%$ em 1965 , passando a $28 \%$ em 1979 e em 1989 , estava próximo de $10 \%$ - estatística americana - (3), devendo-se este fato ao maior conhecimento dos profissionais quanto ao reconhecimento e tratamento da emergência. Após um período de pelo menos $4 \mathrm{~h}$ na recuperação pós-anestésica e outro de $12 \mathrm{~h}$ na UTI o paciente já pode ser encaminhado à enfermaria até completar o período de observação. Portanto, o enfermeiro deve conhecer bem esta intercorrência porque o paciente precisa ser observado e atendido em todos os níveis de atuação da enfermagem, desde a obtenção de dados na execução do histórico de enfermagem no pré-operatório até o preparo para alta na enfermaria.

ARAÚJO, T.L. de; FARO, A.C.M. e LAGANÁ, M.T.C. Body temperature: the nursing care planning for the measurement of the temperature and the attending of the pyrexia and malignant hypertermia. Rev. Esc. Enf. USP., v. 26, n. 3, p. - - , dec., 1992.

The present study showed the body temperature measurement; the choice of measurement instrument and the client attendance with pyrexia and melignant hyperthermia are focused on nursing care planning. hyperthermia.

UNITERMS: Nursing Care. Body temperature measurement. Pyrexia. Malignant

\section{REFERENCIAS BIBLIOGRÁFICAS}

1. ALMEIDA NETO, et al. Hipertermia maligna: relato de dois casos. Rev. Bras. Anestesiol, v. 25, n. 3 , p.191-3, 1985.

2. HARRDY, J.D.: BARD, P. Regulação da temperatura corpórea. In: MOUNTCASTLE, V.B. Fisiologia médica. 13. ed., Rio de Janeiro, Guanabara Koogan, 1978, cap. 56, p.1306-42.

3. JOAQUIM, E.H.G. Hipertermia maligna: diagnóstico precoce com capnografia de gás expirado - dife-rentes quadros clínicos no mesmo paciente - (relato de caso). Rev. Bras. Anestesiol, v. 39, p. 20, 1989.). Suplemento 11.

4. MENDES, F.F. et al. Hipertermina maligna durante a cirurgia ortopédica: relato de um caso. Rev. Bras. Anestesiol, v. 39, n. 3, p.203-6. 1989. 